\title{
The Journey of Organizing and Empowering Yolanda Affected Community: Experiences from a Post Disaster Housing Project in Javier, Leyte, Philippines
}

\author{
Dhino B. Geges \\ Assistant Professor, Department of Social Development and Services \\ College of Human Ecology, University of the Philippines Los Banos, College, Laguna 4031 \\ Chrislyn Joanna P. Faulmino \\ Training Associate, University of the Philippines Los Baños Foundation \\ Inc., College, Laguna 4031
}

\begin{abstract}
The study was conducted to assess the journey of organizing and empowering a Haiyanaffected community that was a beneficiary of a housing project implemented by a private construction company. Specifically, the study sought to (a) characterize the socio-demographic profile of project beneficiaries; (b) determine the roles and contributions of the training participants in the various phases of the housing project; (c) identify support mechanisms of family members to the training participants; (d) discuss the enabling and constraining factors affecting the organizing efforts experienced by the project; and (e) recommend plans to further enhance family participation anchored on the community organizing perspective. The data collection involved community immersion, key informant interviews, and survey. Data were analyzed using descriptive statistics and grounded analysis of qualitative data. It was revealed that most of the respondents were married and had reached a high school level of education. Poverty incidence was relatively high since the average household monthly income fell between PHP 1,800-3,600.00. In terms of livelihood, construction and agriculture-related activities were the most common jobs for men, while women were mostly engaged in service-oriented jobs and community volunteerism. Proactive engagement in organizational development-related trainings was recognized as the key role of most of the mothers as their husbands and sons participated in the masonry skills training program of the construction company. In terms of family support, mothers and wives were identified as a sources of encouragement while fathers or male members of the family provided transport services to assist in the training needs and preparation. Institutional support coming from public and private organizations, high social acceptability, family support system, and improved social capital were also instrumental in accomplishing organizing work and empowerment activities toward resiliency.
\end{abstract}

Keywords: post disaster, housing project, community organizing, empowerment

\section{INTRODUCTION}

Disaster is one of the most life-threatening problems among developing countries like the Philippines, especially considering that the country's geographic position makes it a disasterprone area. Almost 400 national disasters happen yearly which affect more than 230 million people, resulting in an average of 75,000 deaths (Rodriguez et.al, 2008). Likewise, hydro meteorological hazards such as cyclones and typhoons are among the fatal and damaging kind of disasters. 
The Asia Pacific region remains to be on top when it comes to disaster incidences. In 2015, it was accounted that the region experienced 160 out of 344 globally recorded natural disasters. This was equivalent to 16, 046 deaths, a remarkable increase compared to previous years and incurred an economic loss amounting to US\$ 45.1 billion (United Nations Economic and Social Commission for Asia and the Pacific, 2015). The increase in the number of climatological disasters was identified to be the root cause of the increased number of reported natural disasters. The countries which are mostly affected include China, India, Philippines, Indonesia and Pakistan (Guha-Sapir, Hoyois \& Below, 2016). The Philippines was placed also among the top ten countries which are most exposed to compounded type of hazards (Word Development Report, 2015).

Disasters and its impacts are common results of myriad of factors such as unmet development agenda but can still provide other options to further enhance development interventions. Addressing disasters demands both responsive and opportunity-driven development approaches in designing reconstruction projects (Ozerdem, 2003).

Furthermore, previous studies revealed that disadvantaged groups and marginalized communities have a high probability of experiencing a descending twist of weakening after a disaster (Morrow \& Peacock, 1997). Human settlements manifest adverse effects of disasters among impoverished sectors. Housing as part of the physical characteristics of the community is naturally prone to damage especially during the occurrence of strong typhoons and landslide. Consequently, post-disaster housing reconstruction is an immediate concern of the whole community after a disaster strikes.

Post-disaster reconstruction is defined as "a process with potential for creating a resilientbuilt environment or for generating further vulnerabilities to the disaster affected communities" (Chang et. al, 2012, p. 8). Several issues and concerns were recognized by development workers, practitioners and academicians which pose as barriers in the postdisaster reconstructions namely: disaster preparedness, cultural awareness, reconstruction cost, social acceptability and ecological sustainability (Barenstein \& Pittet, 2007; Nazara \& Resosudarmo, 2007; Shaw, 2006 as cited by Chang et. al, 2012).

Post-disaster housing projects are distinctive in nature with so much exceptional sociocultural, economic and technological requirements. Its dynamism is compelling resulting in vibrancy among responses. (Davidson, 2010).

The emerging issues and challenges of housing reconstruction projects as a post-disaster response are similar with those challenges encountered by low-cost housing projects. While there are some notable additions to this like the various scenarios after disasters and the parallel response of local and international organizations towards housing and infrastructure repairs, the period of implementation is included because there is a need to expedite to foster recovery and satisfy the purpose of donor assistance and interventions (Pyles, 2007).

Accordingly, post-disaster housing reconstruction has a myriad of approaches available for implementation (Jha, et.al, 2010). The methods may be community-based or contractor-based. In contractor-based methods, the housing reconstruction is carried out by the contractor while the community has no to limited involvement in the reconstruction process; in contrast, the community-based approach allows the community to have significant amount of control over the project. In developing countries, like the Philippines, the United Nations publication on shelter after disasters underscored the notion of community participation as the key to success amidst reconstruction efforts (UNDRO, 1982). In times of disaster, Maskrey (1989) reiterated 
that people are empowered in the form of community-based organizations to better articulate strategies for recovery and reconstruction which responded to their real needs.

In 2013, the Visayas region was struck by Typhoon Haiyan (Typhoon Yolanda), leaving a total damage and losses worth PHP 132.4 billion (RAY 1, 2013). The establishment of Presidential Assistant for Rehabilitation and Recovery (PARR) in December 2013 became the immediate response of the national government. This newly created unit is expected to handle the management functions on rehabilitation, recovery and reconstruction initiatives from the public and the private sector including key stakeholders.

The design and formulation of the Comprehensive Rehabilitation and Recovery Plan (CRRP) was immediately facilitated to determine the essential plans, projects and programs whether it may be a short term or long term. It is solidly in accordance with policy support coming from RAY which is also responsive among identified needs in the Post Disaster Needs Assessment (PDNA).

The Community Driven Shelter and Livelihood (CDSL) was identified as one of the flagship programs within the plan. CDSL is an alternative shelter program inclined with Disaster Risk Reduction (DRR) to be implemented during post-disaster situations coupled with livelihood planning and implementation. According to PARR, it has the following essential components: building community-driven resilient shelters, initiation of livelihood projects, collective and individual empowerment of disaster victims through shelter building, and inurement of beneficiaries to the value of being primarily responsible for the community's and the environment's care and protection through understanding climate change adaptation and disaster risk reduction actions.

Given this context, it is highly encouraged that housing interventions coming from various interventions must embody the same purpose of CDSL.

Based on a post disaster needs assessment report, 1,035,242 houses were destroyed by Typhoon Yolanda leaving many families homeless and more vulnerable. The resettlement cluster plan sheds light on how to provide disaster resilient housing. The housing sector also has the huge share of resources from the government amounting to PHP 75 billion for the entire program. This is because of the concern attributed to the displacement of thousands of families from at least 116 cities and municipalities who required not only resilient housing but also urgent resettlement from unsafe zones to safer zones.

A private construction company involved in housing programs implemented a project as part of its disaster response initiatives and value-creating engagements. The undertaking significantly supports the interest of the construction company to contribute to the overall goal of the rehabilitation efforts through construction of housing units for the benefit of the Yolanda-affected families. The company focused its housing intervention in the municipality of Javier in the province of Leyte, but had also been operating in Motiong, Samar and Tanauan, Leyte through its masonry skills training program. Part of the entire program was to organize the beneficiaries through the formation of a defined community organization. This has been actualized through the conduct of capacity building and organizational development interventions.

This scenario was also supported by Chang et. al (2010) when they explained that academic institutions and non-government organizations have paid attention to making reconstruction 
projects more participatory and that the scarcity of needed resources and the ability to undergo the rebuilding activities still not yet been studied thoroughly.

Based on the case studies of Sadiqi et. al (2011), majority of the failures of post-disaster housing projects being implemented can be attributed to problems related to the following: community participation, resettlement concerns, dishonesty, financial related issues, and neglecting local culture and felt needs. There were also issues on land availability, LGU cooperation, safety and security.

Community participation in the literature is underscored as an essential factor for postdisaster housing projects to take off (Sadiqi et. al, 2011). The effectiveness of the communication process is indispensable in the phases of rebuilding. It provides a push for a better understanding of the local culture including the direction of the information flow across all the stages of reconstruction activities.

Ophiyandri et.al. (2010) recommended that there is a need to emphasize the community's level of participation such as collaboration especially when defining a community-based approach in the milieu of a post-disaster housing reconstruction project.

The project activities must not only pay attention to the physical activities itself but must also consider how to enhance the role of various stakeholders and community members' contribution in the successful post housing reconstruction project (Federation of Canadian Municipalities, 2001).

This study sought to assess the journey of organizing and empowering a Haiyan-affected community in the context of a housing project. Specifically, it aimed to (a) characterize the socio-demographic profile of project beneficiaries; (b) determine the roles and contributions of the training participants in the various phases of the housing project; (c) identify support mechanisms of family members to the training participants; (d) discuss the enabling and constraining factors that affected the organizing efforts experienced by the project; and (e) recommend plans for further enhancement of family participation anchored in the community organizing perspective.

\section{Locale of the Study}

\section{METHODOLOGY}

Javier was formerly part of the Municipality of Abuyog. It is a fourth-class municipality and among the youngest ones in the Leyte province. It is composed of 28 barangays in 15,270 hectares of land. The entire municipality is predominantly agricultural in nature. Likewise, it is characterized geographically by mountains, hills, plains, plateaus, and rolling plains. The postdisaster housing project is located at Sitio Mapula, Barangay Zone 1, Javier. 


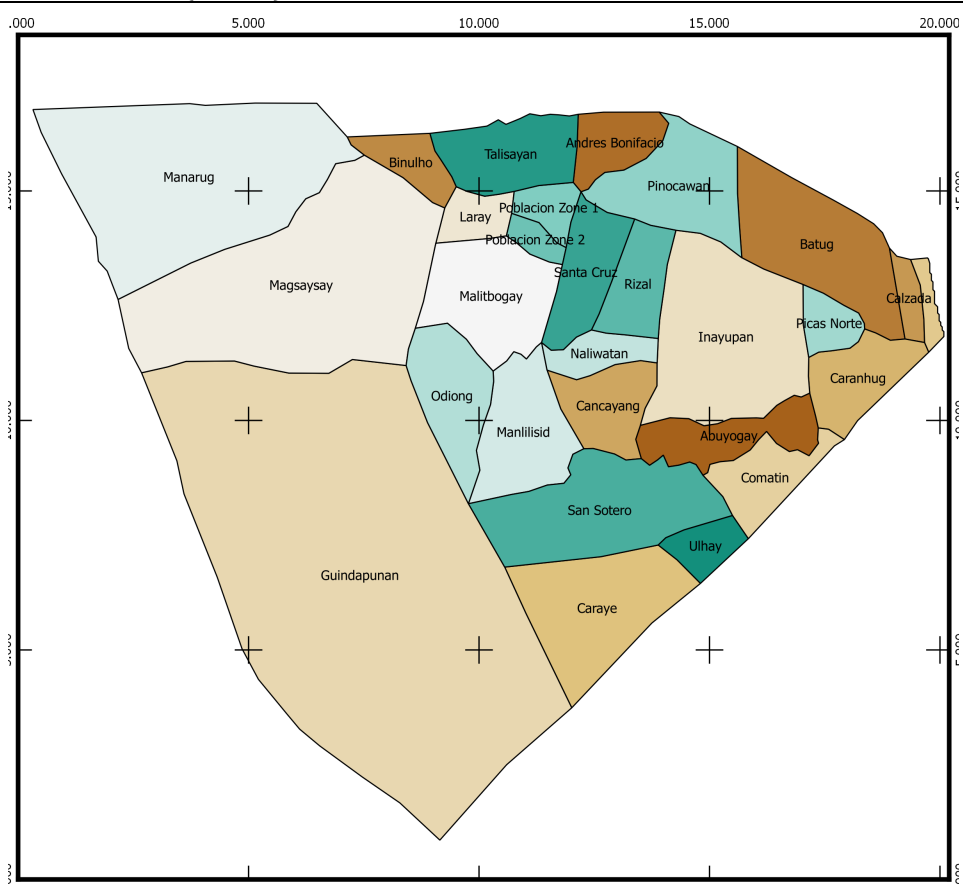

Figure 1. Municipal Map of Javier, Leyte

\section{Research Design}

This research utilized a descriptive case study approach. Survey data were analyzed using descriptive statistics. Respondents of the study were the participants of the Organizational Development trainings and workshops in the areas. Key informant interviews, Focus Group Discussion (FGD), and field immersion were also employed in the study. Respondents of the study were the training participants from the capacity building and organizational development component of the project covering about $90 \%(n=25)$ of the total number of training participants $(\mathrm{N}=25$ to 28$)$. Secondary data were gathered also from the local government units (LGU), private sector and reports from non-government organizations. Ethical considerations were also secured during period of the study.

\section{Data Analysis and Presentation}

Results were analyzed both quantitatively and qualitatively. Descriptive statistics and grounded and thematic analyses of data were employed. Findings of the study were presented to the community including key stakeholders.

\section{Scope and Limitations of the Study}

The study focuses only on the case of a post disaster housing project in the Municipality of Javier thus findings were only applicable to the selected site. This research only covers the preliminary phase covering the period of almost one year. Since community organizing does not happen in a short period of time, it is expected that there are still findings that can be documented even after the completion of the housing project.

\section{RESULTS AND DISCUSSION}

\section{The Capability Approach in Post-Disaster Housing Project}

The process of how the construction is done makes it more valuable than just considering the physical construction of houses (Oliver-Smith, 1991). One of the noticeable constraints among beneficiaries and stakeholders is resource mobilization (Russell, 2005; Singh and Wilkinson, 2008; Zuo et al., 2009). This has been supported by Chang et.al (2012) when they reiterated the need to realize "the critical factors that affect post-disaster resource and to enhance capabilities toward managing disaster recovery projects" (p. 558). Given the complexities of 
issues and challenges that need to be managed hand in hand, community members must perform various roles and responsibilities to build a sense of ownership which leads to sustainability of the project. Although there were prior predicaments about the community's technical skills and knowledge, the project beneficiaries must have an equal share in supporting their right to development.

This research explores the application of Sen's capability approach in the context of a postdisaster reconstruction project. The human development paradigm which clings to the capability approach must still at be the center of all the rehabilitation efforts and initiatives. The expansion of project beneficiaries' capacities must be enhanced. The promotion of an individual's ability to do or to be can further contribute to the success of a community-driven housing reconstruction project. The evaluation of equal participation must not only rely on functioning but also on the real essence of freedom arising from a wider range of choices and opportunities.

This has been the take-off on how the journey of organizing disaster-stricken communities is contextualized. The techniques employed by the project include community profiling and community dialogues/consultations with project beneficiaries and the local government unit (LGU) to understand pathways reaching the beneficiaries' enjoyment of development by having freedom in many forms and shapes.

\section{A. Socio-demographic Characteristics of the Respondents}

More than half of the respondents were aged 37 to 52 (56\%) and were married (64\%). They were household heads or parents from the families selected to be beneficiaries of the housing project. In addition, majority of them were female (72\%) and attendees of the capacity building trainings since husbands commonly attended income-generating activities. Almost half of the respondents reached the high school level $(40 \%)$ while a considerable number (24\%) had no formal education. Almost all (92\%) were Roman Catholics.

Respondents either had no source of income (28\%) or were blue-collar workers (72\%). The men were commonly engaged in construction-related and farming activities while the women had service-oriented work with flexible working hours such as laundry and salon services or community service work as Barangay Health Workers or volunteers in Community Health Teams.

More than one-fourth (32\%) of the respondents had a monthly income of PHP 1,801 to PHP 3600. Almost all of the projects beneficiaries' families fell below the poverty line. This is evident in the data from the National Anti-Poverty Commission stating that the province of Leyte is one of the poorest provinces in the country. This increases the beneficiaries' vulnerability as experiences in the Philippines have shown that the poor and the communities to which they belong are the most vulnerable to disasters (Luna, 2009). 
Table 1. Socio-demographic characteristics of the respondents.

\begin{tabular}{|c|c|c|}
\hline Characteristic & $\begin{array}{c}\text { Frequency } \\
(n=25)\end{array}$ & Percentage (\%) \\
\hline \multicolumn{3}{|l|}{ Age } \\
\hline $21-28$ & 3 & 12 \\
\hline $29-36$ & 3 & 12 \\
\hline $37-44$ & 8 & 32 \\
\hline $45-52$ & 6 & 24 \\
\hline $53-60$ & 2 & 8 \\
\hline $61-68$ & 3 & 12 \\
\hline \multicolumn{3}{|l|}{ Sex } \\
\hline Female & 18 & 72 \\
\hline Male & 7 & 28 \\
\hline \multicolumn{3}{|l|}{ Civil Status } \\
\hline Single & 0 & 0 \\
\hline Married & 16 & 64 \\
\hline Separated & 1 & 4 \\
\hline Widowed/Widower & 1 & 4 \\
\hline Live-in/Cohabiting & 7 & 28 \\
\hline \multicolumn{3}{|l|}{ Religion } \\
\hline Roman Catholic & 23 & 92 \\
\hline Assembly of God & 1 & 4 \\
\hline Born Again Christian & 1 & 4 \\
\hline \multicolumn{3}{|l|}{ Educational Attainment } \\
\hline No formal education & 6 & 24 \\
\hline Elementary level & 0 & 0 \\
\hline Elementary graduate & 5 & 20 \\
\hline High school level & 10 & 40 \\
\hline High school graduate & 3 & 12 \\
\hline College level & 0 & 0 \\
\hline College graduate & 1 & 4 \\
\hline \multicolumn{3}{|l|}{ Livelihood } \\
\hline None & 7 & 28 \\
\hline Blue collar job & 18 & 72 \\
\hline \multicolumn{3}{|l|}{ Household Income } \\
\hline 0 & 1 & 4 \\
\hline $1-1800$ & 5 & 20 \\
\hline $1801-3600$ & 8 & 32 \\
\hline $3601-5400$ & 4 & 16 \\
\hline $5401-7200$ & 4 & 16 \\
\hline $7201-9000$ & 3 & 12 \\
\hline
\end{tabular}

\section{B. Role of Training Participants in the Various Phases of the Capacity-Building Activities}

The duration of the capacity-building activities for community organizing and organizational development was from May 2015 to February 2016 as it was recognized that the communitybased methods of post-disaster reconstruction requires long pre-construction processes (Ophiyandri et al., 2010). The project adhered to the operational framework of the CDSL component of the rehabilitation as per the guidelines set by the Office of the Presidential 
Assistant for Rehabilitation and Recovery (OPPAR) which includes the implementation of both shelter-building implementation and social preparation shown in Table 2.

Table 2. Social Preparation Activities and Shelter Building (adopted from OPPAR, 2015)

\begin{tabular}{|c|c|c|}
\hline Components & Major Activities & Specific Activities/ Details \\
\hline & SOCIAL PREPARATION & \\
\hline \multirow[t]{4}{*}{ Community Preparation } & $\begin{array}{l}\text { 1.1 Community Integration } \\
\text { and Partnership }\end{array}$ & $\begin{array}{l}\text { Community Driven } \\
\text { Shelter and Livelihood } \\
\text { Orientation during } \\
\text { community assemblies } \\
\text { Orientation-seminar on } \\
\text { hazard maps and other } \\
\text { technical tool at the } \\
\text { community level }\end{array}$ \\
\hline & 1.2 Community Profiling & 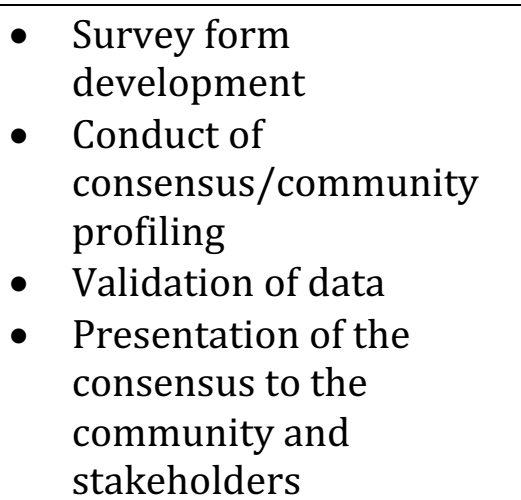 \\
\hline & $\begin{array}{l}1.3 \text { Identification of } \\
\text { resettlement area }\end{array}$ & $\begin{array}{l}\text { - Land Identification } \\
\text { /Searching } \\
\text { - Coordination with the } \\
\text { LGU } \\
\text { - Negotiation with the } \\
\text { owner, if privately } \\
\text { owned }\end{array}$ \\
\hline & $\begin{array}{l}\text { 1.4 Validation of Site } \\
\text { Suitability }\end{array}$ & $\begin{array}{ll}\text { - } & \text { Legal research } \\
\text { - } & \text { Topography } \\
\text { - } & \text { Geo-hazard assessment } \\
& \text { and relocation survey }\end{array}$ \\
\hline $\begin{array}{l}\text { Community Organizing and } \\
\text { Consensus Building }\end{array}$ & Organizing the community & $\begin{array}{ll}\text { - } & \text { Facilitation } \\
\text { - } & \text { Visioning } \\
\text { - } & \text { Learning } \\
\text { - } & \text { SWOT Analysis } \\
\text { - } & \text { Shelter and Livelihood } \\
& \text { Planning } \\
\text { - } & \text { Formation of working } \\
& \text { groups }\end{array}$ \\
\hline Capacity Building & 3.1 Shelter Construction & $\begin{array}{l}\text { Trainings on carpentry, } \\
\text { repair works, retrofitting } \\
\text { and other labor-related } \\
\text { working training } \\
\text { sessions }\end{array}$ \\
\hline
\end{tabular}




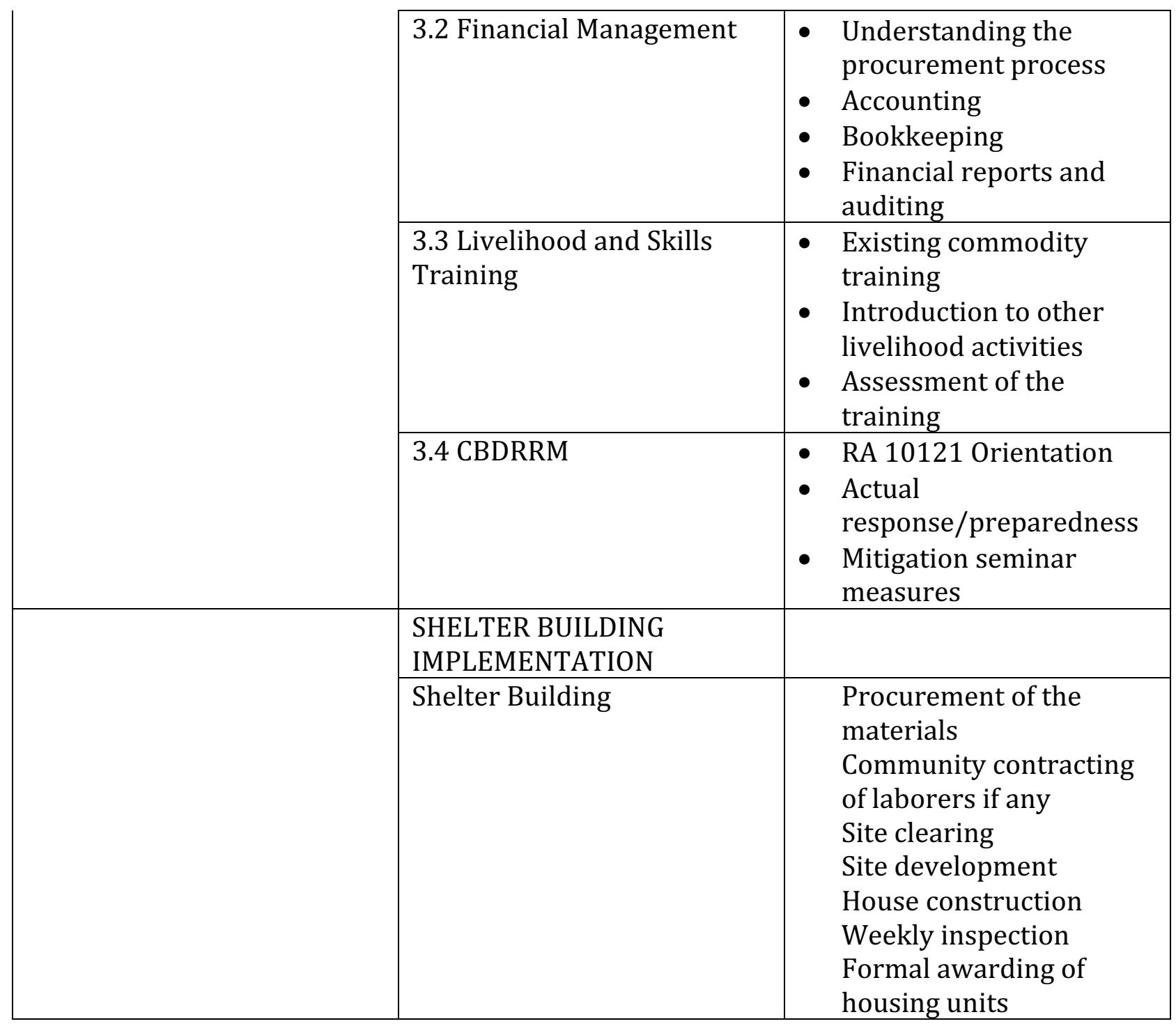

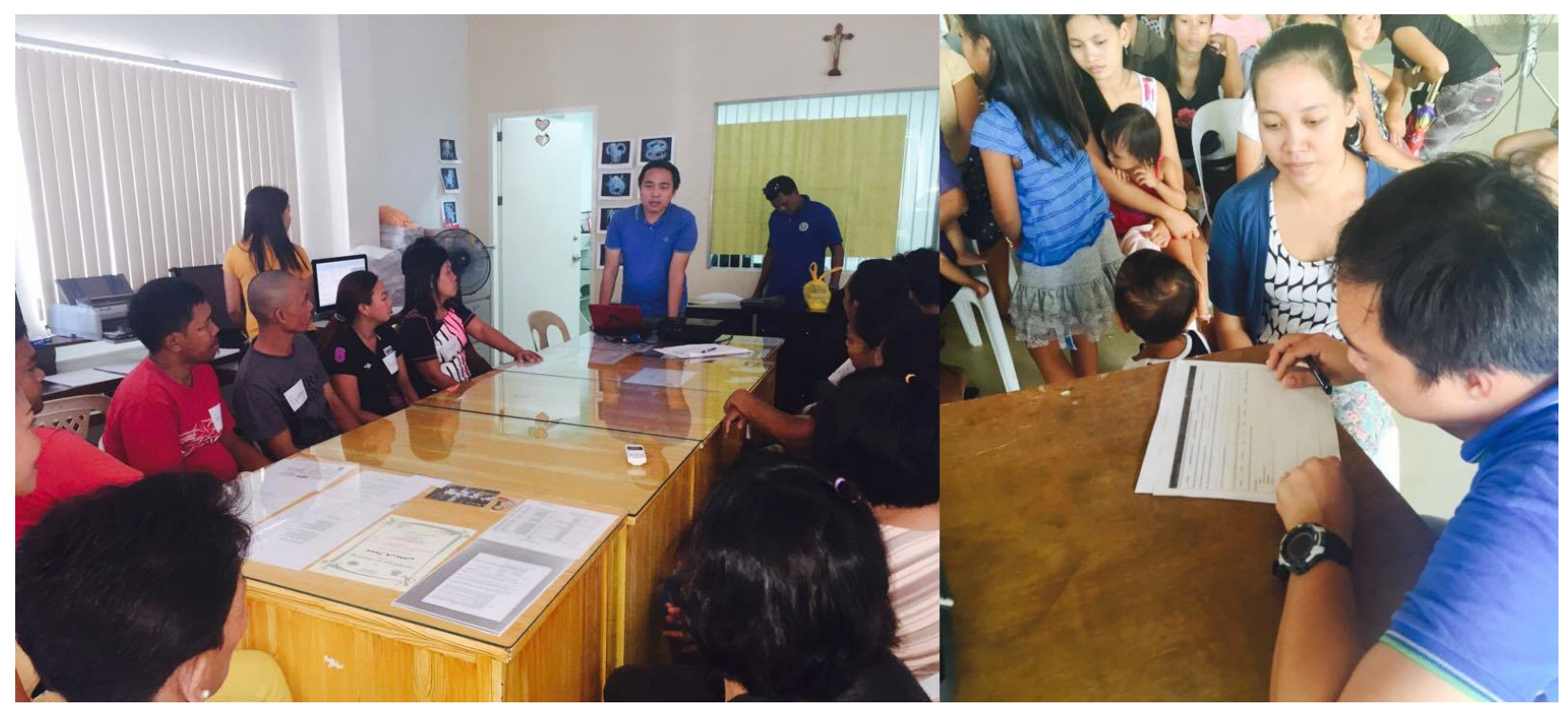

Figure 2a. Community dialogue and community profiling (Photo taken by Faulmino, 2015)

The early phases of project implementation constitute community integration and partnership, community profiling, identification of resettlement area, and validation of site suitability. For 
the most part, participation of the beneficiaries was limited to attendance and cooperation. This phase was shortly followed by community organizing and consensus building, which included organizing the beneficiaries through seminars and workshops on team building and laying down organizational foundations such as naming the organization and crafting its Vision, Mission, Goals, and Objectives. The beneficiaries named their Homeowners' Organization "Bag-o Nga Paglaum," which means "new hope."

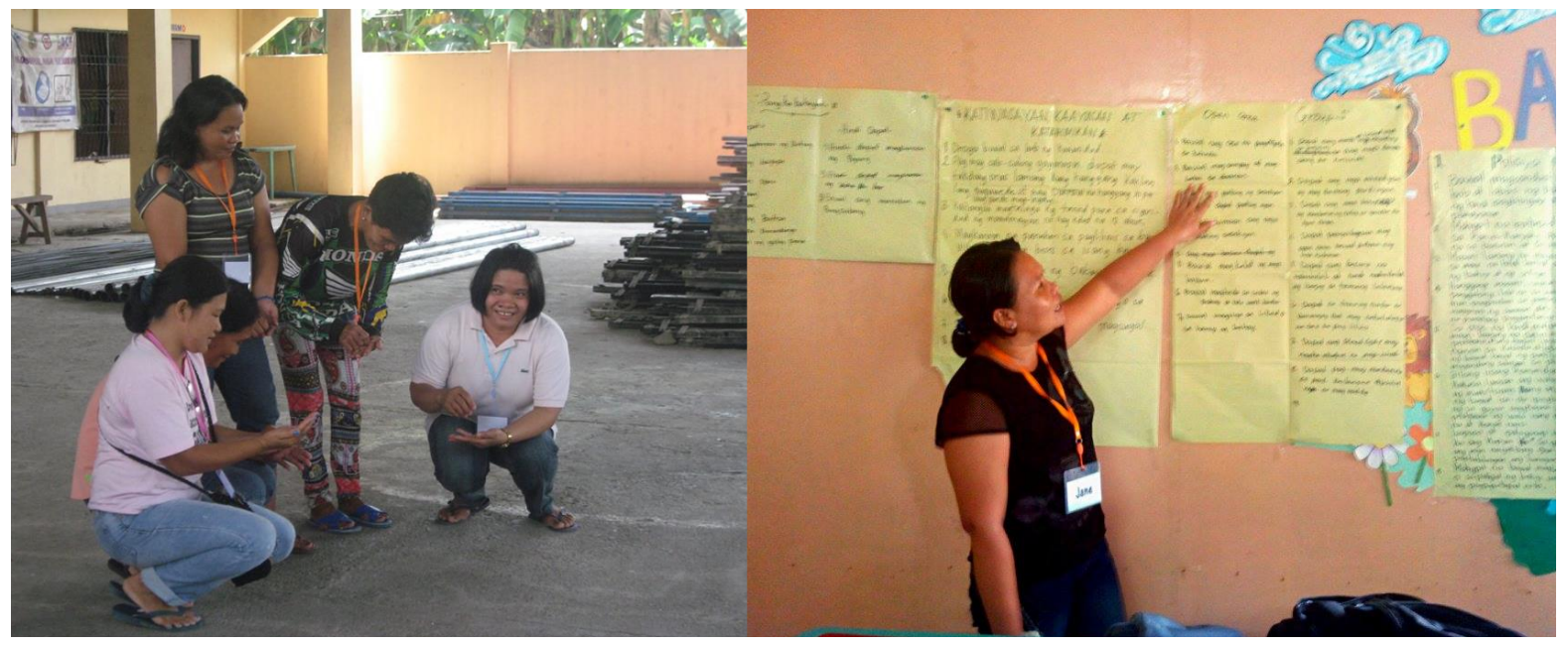

Figure 2b. Community based trainings (Photo taken by Faulmino, 2015)

The participation of the respondents at this phase remained to be predominantly through attending the trainings. Their attendance was significant particularly during this phase as they came from different barangays (Zones 1 and 2). According to the respondents, their attendance to the training activities was instrumental in their unity. A housing project in Dinar, Turkey caused socio-cultural problems and late environmental adaptation for the relocated families upon living in apartment buildings with families that that they do not know (Ozden, n.d.). Creating social ties among the beneficiaries as early as this stage would prevent similar concerns.

The coordination with the LGU of Javier, Leyte was attended to by the facilitator of the trainings while the regional Department of Social Welfare and Development (DSWD) made announcements to the beneficiaries for the schedule of housing project activities. As early as this phase, the gradual process of empowerment began by designating tasks to two point persons for coordination purposes including food preparation and logistical support.

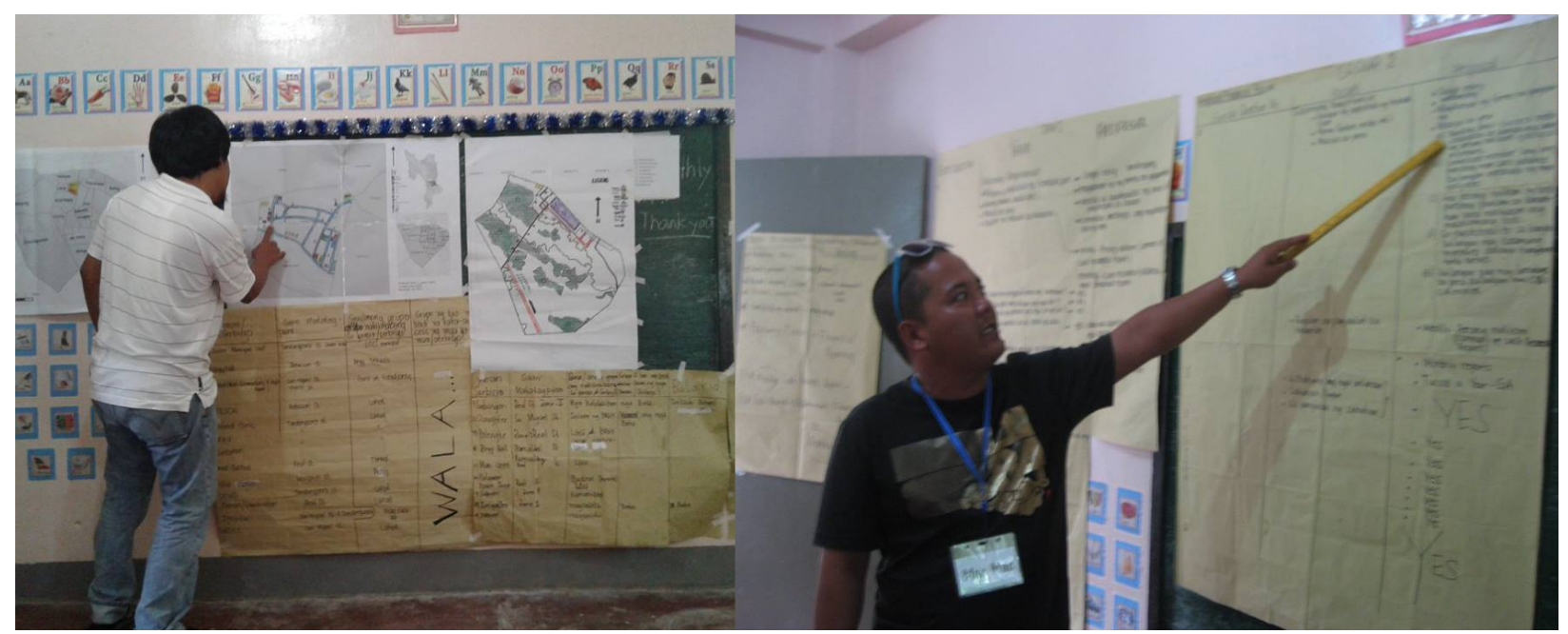


Figure 2c. Community-based training workshop (Photo taken by Faulmino, 2015)

Moving forward brought the beneficiaries to the capacity-building phase in which the knowledge and skills of the beneficiaries in shelter construction, financial management, livelihood and skills training, and community-based disaster risk reduction and management were further enhanced. The outputs created during the trainings in this phase also contributed to the advantage of ensuring that the agreements fit local culture, wisdom, and customs of the community. Such examples were the crafting of their estate management policies and disaster preparedness plans.

It was also observed during this phase that more participants assisted in food preparation and engaged in logistical support like preparing training equipment needs and cleaning up the venue. They believed that those were important tasks since it allowed the facilitator to focus on the training activities. "Para hindi na nila isipin 'yung mga gawain na iyon [So that they will not think about those tasks anymore]," said one respondent.

Other participants with leadership potential had also risen up at this point as evidenced by the addition and changes in leadership assignments. Respondents expressed that they learned a lot from the training workshops, and that this had built their confidence, which was one of the advantages of the community-based method of post-disaster housing reconstruction projects (Ophiyandri, 2010).

Towards the end of the social preparation component, participants were given opportunities to apply acquired capacities by conducting re-echo sessions and coordinating with all housing project beneficiaries. The empowerment of the participants were seen not only at an individual level, but also at the organizational level. The core group members took full charge of conducting the general assembly meetings to relay the outputs of the trainings they attended.

Improvements on their coordination and communication capabilities were likewise observed as the participants started coordinating with the LGU themselves for concerns and needs related to the trainings. It was also noted that the core group leaders gained the initiative to update the training facilitators on the conduct of the re-echo sessions and other activities from the other components of the housing project. This situation has been highlighted in the literature by pointing out that the effectiveness of the communication process is indispensable in the phases of rebuilding because it provides a push for a better understanding of the local culture including the direction of the information flow across all the stages of reconstruction activities.

Although the roles of the participants might be broadly categorized under each phase, overlaps and continuity of their roles across phases might be observed. The dynamism of their roles was also acknowledged as the community activities were expected to continue beyond project life. 
Table 3. Roles of training participants in the various phases of the capacity building activities.

\begin{tabular}{|l|l|c|c|}
\hline Role Participation & \multicolumn{1}{|c|}{ Phases Observed } & \multicolumn{1}{|c|}{$\begin{array}{c}\text { Frequency } \\
\text { (n=25) }\end{array}$} & $\begin{array}{c}\text { Percentage } \\
\text { (\%) }\end{array}$ \\
\hline Attendance & $\begin{array}{l}\text { Community Preparation, } \\
\text { Community Organizing and } \\
\text { Consensus Building, Capacity } \\
\text { Building }\end{array}$ & 25 & 100 \\
\hline Food preparation & $\begin{array}{l}\text { Community Organizing and } \\
\text { Consensus Building, Capacity } \\
\text { Building }\end{array}$ & 10 & 40 \\
\hline $\begin{array}{l}\text { Coordination and } \\
\text { communication }\end{array}$ & $\begin{array}{l}\text { Community Organizing and } \\
\text { Consensus Building, Capacity } \\
\text { Building }\end{array}$ & 3 & 12 \\
\hline $\begin{array}{l}\text { Transportation and } \\
\text { logistical support }\end{array}$ & $\begin{array}{l}\text { Community Organizing and } \\
\text { Consensus Building, Capacity } \\
\text { Building }\end{array}$ & 5 & 20 \\
\hline $\begin{array}{l}\text { Conduct of re-echo } \\
\text { sessions }\end{array}$ & Capacity Building and beyond & 12 & 48 \\
\hline
\end{tabular}

Based on the Philippine Business for Social Progress' ${ }^{1}$ (PBSP) Community Organizing Framework, the project had accomplished the Conscientization phase. The project beneficiaries were able to identify problems and needs, express willingness to change, and articulate their desired state or condition. In addition to this, their core group and their initial action plans and committees which constituted Constituency Building in terms of group formation had been actualized. The beneficiaries then moved moving towards Institutionalization, the final phase of Community Organizing.

The differences of the contribution of the participants might also be analyzed in terms of gender and family roles. The women were most typically involved in food preparation, particularly in cooking and washing of dishes. They usually took roles in writing workshop reports, recording minutes of meetings, and other secretariat duties. Cleaning up of the training venue was also usually done by the women.

On the other hand, men also participated in food preparation, but their tasks were mostly those that required strength, like fetching water and running errands for food ingredients and snacks that needed to be bought. Although the men rarely took the responsibility of writing workshop reports, they still contributed mostly on ideas as inputs. In logistical support, they assisted in collecting needed equipment and training materials and assisted in other tasks that other members requested from them.

It was noted that during the trainings, both genders participated in reporting outputs and expressing ideas and opinions.

1 PBSP is a corporate led social development foundation that implements various Corporate Social Responsibility programs in the Philippines 
Table 4. Roles and/or contributions of participants in relation to sex

\begin{tabular}{|l|l|}
\hline \multicolumn{1}{|c|}{ Women } & \multicolumn{1}{c|}{ Men } \\
\hline - \begin{tabular}{l}
\multicolumn{1}{|c|}{ Preparation and reporting of workshop } \\
outputs (4)
\end{tabular} & $\bullet$ Food preparation (2) \\
- $\begin{array}{l}\text { Cooperation in training activities and } \\
\text { contribution of ideas (4) }\end{array}$ & $\bullet \begin{array}{l}\text { Cooperation in training activities and } \\
\text { contribution of ideas (2) }\end{array}$ \\
- Food preparation and management (7) & - Assistance in other tasks (1) \\
- Venue cleanup (6) & - Logistical support (1) \\
\hline
\end{tabular}

\section{Family Support}

In light of post-disaster housing projects catering to the needs at the family level, the indirect roles and contributions of the participants' household members were also acknowledged and looked into. Project beneficiaries shared the common vision of moving into their new houses and the capacity building activities were part of the reconstruction for the resiliency process.

Spouse. Results showed that the spouses of the training participants provided much support. These included food preparation, taking charge of domestic chores, and looking after the children when the participants were attending the capacity building activities. This gave the participants peace of mind in attending the trainings-knowing that household tasks were taken care of. Another support was that of spouses encouraging the participants to attend the trainings with some even extending their assistance to their spouses in preparing for the training needs. One of the spouses of the respondents attended the masonry skills training program component of the housing project. Their case illustrated an example of a family collaboratively in the process of post-disaster reconstruction and empowerment activities. This scenario also clearly shows women's potential contribution in the reconstruction activities which is often neglected because of the misconception towards their capacity (Ariyabandu, 2009; Merilyn, 2006; UNDP, 2010).

Children. The children of the training participants also contributed in the support system of the training participants. They did household chores and supported their parents in attending the trainings. It may also be noted that some respondents acknowledged the studies of their children as contribution as they viewed as important in the entirety of the empowerment process. Likewise, one of the respondents' children also attended the masonry skills training program .

Other household members. Other household members, which typically were members of the extended family, provided support by looking after the training participants' children and taking over household chores. 
Table 5. Support Provided by Family Members to the Training Participants

\begin{tabular}{|c|c|c|}
\hline Spouse & Child/Children & Other household members \\
\hline 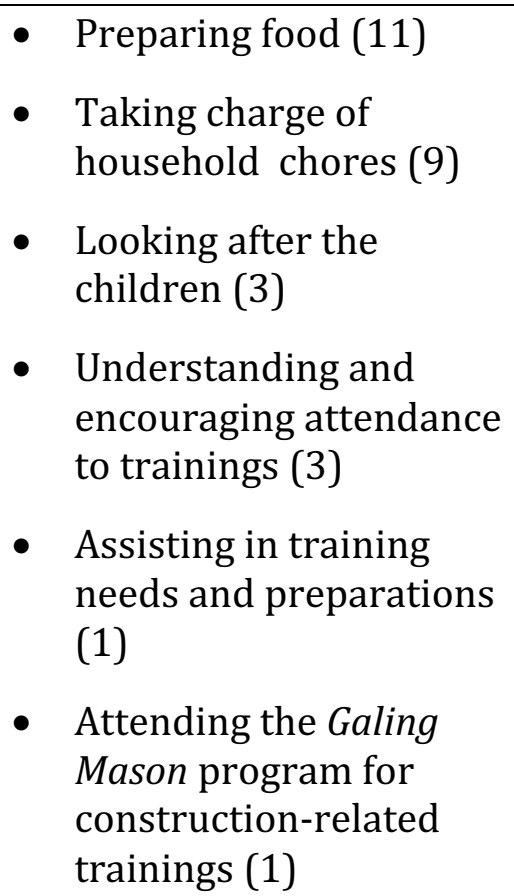 & $\begin{array}{l}\text { - Taking charge of } \\
\text { household chores (3) } \\
\text { - Studying (2) } \\
\text { - Understanding and } \\
\text { encouraging attendance } \\
\text { to trainings (2) } \\
\text { - Attending the Galing } \\
\text { Mason program for } \\
\text { construction-related } \\
\text { trainings (1) }\end{array}$ & $\begin{array}{l}\text { - Taking charge of } \\
\text { household chores (2) } \\
\text { - Looking after the children } \\
\text { (1) }\end{array}$ \\
\hline
\end{tabular}

\section{Enabling and Constraining Factors Affecting the Housing Project Implementation}

Enabling factors identified to have affected project implementation were institutional support from private and public organizations, use of holistic methods, volunteerism, high social acceptability and initiative, and family support.

Lack of resources and sustainability were common problems in housing reconstruction efforts, hence institutional support coming from both private and public organizations provided a more well-rounded approach in project implementation. Funding from the private organization covered project realization, and the involvement of the LGU ensured sustainability of structures and systems installed during the housing project implementation. LGU commitment to providing promptly appropriate land and basic necessities of sewerage system, water and electricity was also needed for the success of the project.

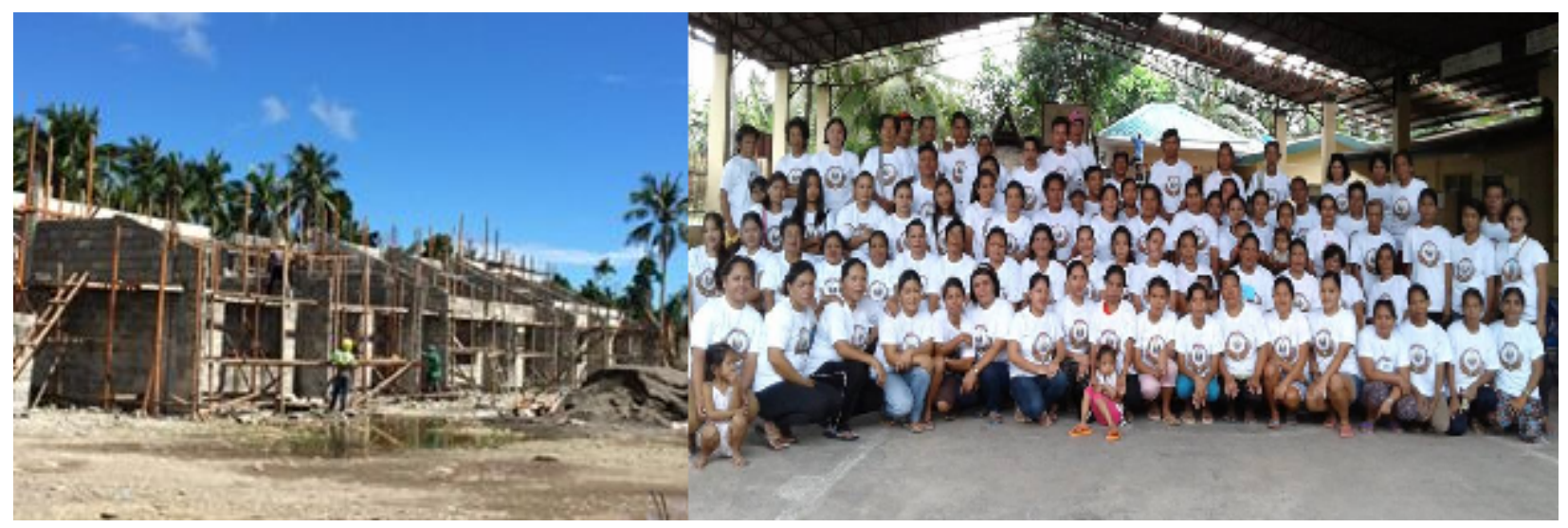

Figure 3b. Ongoing housing construction (Left) and the project beneficiaries (Right) (Photo taken by Geges \& Faulmino, 2016) 
The use of both the contractor-based and community-based approaches allowed for a holistic and well-rounded housing project design. The structural design of the houses and materials used were carefully designed according to the hazards present and adhered to sustainable construction. In complement, the community-based approach prevented the occurrence of common problems experienced in housing projects. The set of activities employed promoted creation of plans and systems that fit local culture and customs. Sustainability of the entire project was valued through building the sense of ownership among community members. This also resulted in improved social capital and unity among project beneficiaries. It had also allowed for community participation through food preparation which also served as a livelihood opportunity for the beneficiaries and further increased their motivation to participate in the project activities.

Volunteerism and initiative of the training participants were also instrumental in project progress and initial success. Such cooperation eased project implementation and improved efficiency.

High social acceptability towards the project also facilitated the project implementation's success. Project beneficiaries came from poor families and lived in houses that they either rented or shared with extended family, and could neither afford to buy houses nor lands of their own. The quality of the project houses also gave them security that it could withstand strong weather conditions such as typhoons.

Lastly, without family support, the process of empowerment would not have been possible for the housing project. Therefore, the indirect contribution of family members cannot be undermined.

In contrast, factors that constrained implementation were beneficiary unbelief, inconsistent attendance of some training participants and conflicts among participants, if not resolved. Previous housing projects in Javier, Leyte that did not take off caused hesitation and unbelief among beneficiaries, which in turn affected the early stages of project implementation in terms of gathering core group participants for the trainings. In between project implementation, inconsistent attendance among participants also hindered success since the trainings were strategically designed as interrelated sets of activities to be learned in continuity. Inconsistent attendance disrupted learning process and led to feelings of isolation for the inconsistent attendees. Finally, conflicts that will inevitably arise among participants, if not resolved, can discourage them and ruin progress developed so far. It is therefore of utmost importance that conflict resolution be discussed during the early phases of implementation and problems be resolved before long with the help of the community organizer and other supporting institutions.

\section{CONCLUSIONS AND RECOMMENDATIONS}

The study considered the journey of organizing and empowering Yolanda-affected families in the context of a post-disaster housing project. While this engagement was a public-private type of engagement, the affected families catered as beneficiaries had direct involvement and acceptable level of participation especially in the technical training under the masonry skills training program of the construction company. Taking into consideration the notion of sustainability, these beneficiaries were organized into a legitimate community organization. Likewise, as a startup organization they traversed the phases of conscientization and constituency building. Family members also had significant roles which had been performed along the way to accomplish the common goal of collectively pursuing the housing project and its overall aim in building a disaster-resilient community. 
Furthermore, based on the abovementioned results, the following plans are being proposed:

1. Female members of the family must explore the opportunity to participate in the masonry skills training program to provide livelihood opportunities in the long run;

2. The members of the organization must be assisted in defining their pathway to the institutionalization stage of community organizing to maximize the untapped potential of the physical community as well as its existing resources; and

3. Strengthen partnership between public institutions and private organizations to address the other social needs of the community such as water, electricity and sewerage system.

\section{References}

Ariyabandu, M. M. (2009) Sex, gender and gender relations in disasters. In Women, gender and disaster global issues and Initiatives, eds. E. Enarson and P. G. D. Chakrabarti, 1 online resource (399 p.). New Delhi: SAGE India.

Barenstein, J.D. and Pittet, D. (2007) Post-disaster housing reconstruction: current trends and sustainable alternatives for tsunami-affected communities in coastal Tamil Nadu. Institute for Applied Sustainability to the Built Environment, University of Applied Sciences of Southern Switzerland, Canobbio.

Chang, Y., Wilkinson, S., Potangaroa, R., \& Seville, E. (2012) Resourcing for post-disaster reconstruction: a comparative study of Indonesia and China. Disaster Prevention and Management: An International Journal, Vol. 21 Issue: 1, pp.7-21.

Chang, Y., Wilkinson, S., Potangaroa, R. and Seville, E. (2010a) Resourcing challenges for post- disaster housing reconstruction: a comparative analysis. Building Research and Information, Vol. 38 No. 3, pp. 247-64.

Davidson, C. H. (2010) Multi-actor arrangements and project management.

Federation of Canadian Municipalities. (2001) Local Government and Poverty Reduction: Report for Instanbul. Ottawa: The Federation.

Guha-Sapir D, Hoyois Ph., Below. R. (2016) Annual Disaster Statistical Review 2015: The Numbers and Trends. Brussels: CRED

Jha, A.K., Barenstein, J.D., Phelps, P.M., Pittet, D. \& Sena, S. (2010) Safer homes, Stronger Communities: A Handbook for Reconstructing after Natural Disasters. Washington: The International Bank for Reconstruction and Development / The World Bank.

Maskey, A. (1989). Disaster Mitigation: A community based approach. Oxford: Oxfam

Merilyn, C. (2006) Not through women's eyes: photo-essays and the construction of a gendered tsunami disaster. Disaster Prevention and Management 15 (1):202-212.

Morrow, B. \& Peacock, W. (1997). Disasters and Social Change: Hurricane Andrew and the Reshaping of Miami? New York: Routledge

Nazara, S. \& Resosudarmo, B.P. (2007). Aceh-Nias Reconstruction and Rehabilitation: Progress and Challenges at the End of 2006. Discussion Paper, Asian Development Bank Institute (ADBI), Tokyo.

Oliver-Smith, A. (1991) Successes and failures in post-disaster resettlement. Disasters, Vol. 15 No. 1, pp. 12-23.

Ophiyandri, T., Amaratunga, D, \& Pathirage, C. (2010) Community Based Disaster Housing Reconstruction: Indonesian Perspective. Proceeding of CIB World Congress. 10-13 May 2010. Salford, United Kingdom

Ozden, A. T. (n.d) Developing a Model for Community Involvement in Post-Disaster Housing Programmes. Middle East Technical University

Ozerdem, A. (2003) Disaster as Manifestation of Unresolved Development Challenges: The Marmara Earthquake, Turkey in M. Pelling(ed) Natural Disasters and Development in a Globalizing World. London: Routledge.

Pyles, L. (2007). Community Organizing for Post Disaster Social Development: Locating Social Work. Sage Publications.

Rodriguez, J., Vos, F., Below, R. \& Guha-Sapir, D. (2009) Annual Disaster Statistical Review 2008: The Number and Trends. Center for Research on the Epidemiology of Disasters. 
Russell, T.E. (2005) The humanitarian relief supply chain: analysis of the 2004 South East Asia earthquake and Tsunami. Master thesis, Engineering Systems Division, Massachusetts Institute of Technology, Cambridge, MA.

Sadiqi, Z., Coffey, V., \& Trigunarsyah, B. (2011) Post-disaster housing reconstruction: challenges for community participa- tion. In Proceedings of the International Conference on Building Resilience: Interdisciplinary approaches to disaster risk reduction, and the develop- ment of sustainable communities, Heritance Kandalama, Sri Lanka.

Shaw, R. (2006) Indian Ocean tsunami and aftermath: need for environment-disaster synergy in the reconstruction process. Disaster Prevention and Management, Vol. 15 No. 1, pp. 5-20.

Singh, B. and Wilkinson, S. (2008) Post-disaster resource availability following a Wellington Earthquake: aggregates, concrete and cement. I-Rec 2008 Building Resilience: Achieving Effective Post-Disaster Reconstruction, Christchurch, 30 April-2 May

United Nations Office of the Disaster Relief Coordinator (1982) Shelter after disaster: Guidelines for assistance.

UN ESCAP (2015) Disasters without borders: Regional Resilience for Sustainable Development. Asia-Pacific Disaster Report 2015.

World Development Report. (2015). International Bank for Reconstruction and Development / The World Bank 1818 H Street NW, Washington, DC 20433

Zuo, K., Potangaroa, R., Wilkinson, S. and Rotimi, J.O.B. (2009) A project management prospective in achieving a sustainable supply chain for timber procurement in Banda Aceh, Indonesia. International Journal of Managing Projects in Business, Vol. 2 No. 3, pp. 386-400. 